\title{
One-pot synthesis of benzofurans via heteroannulation of benzoquinones
}

Pirouz, Maryam; Saeed Abaee, M.; Harris, Pernille; Mojtahedi, Mohammad M.

Published in:

Heterocyclic Communications

Link to article, DOI:

10.1515/hc-2020-0120

Publication date:

2021

Document Version

Publisher's PDF, also known as Version of record

Link back to DTU Orbit

Citation $(A P A)$ :

Pirouz, M., Saeed Abaee, M., Harris, P., \& Mojtahedi, M. M. (2021). One-pot synthesis of benzofurans via heteroannulation of benzoquinones. Heterocyclic Communications, 27(1), 24-31. https://doi.org/10.1515/hc2020-0120

\section{General rights}

Copyright and moral rights for the publications made accessible in the public portal are retained by the authors and/or other copyright owners and it is a condition of accessing publications that users recognise and abide by the legal requirements associated with these rights.

- Users may download and print one copy of any publication from the public portal for the purpose of private study or research.

- You may not further distribute the material or use it for any profit-making activity or commercial gain

- You may freely distribute the URL identifying the publication in the public portal

If you believe that this document breaches copyright please contact us providing details, and we will remove access to the work immediately and investigate your claim. 


\section{Maryam Pirouz, M. Saeed Abaee*, Pernille Harris, Mohammad M. Mojtahedi One-pot synthesis of benzofurans via heteroannulation of benzoquinones}

https://doi.org/10.1515/hc-2020-0120

Received December 02, 2020; accepted February 15, 2021.

Abstract: Three different reactions were explored leading to the synthesis of various benzofurans. All reactions took place under $\mathrm{AcOH}$ catalysis in a one-pot manner. As a result, benzoquinone derivatives underwent heteroannulation with either itself or cyclohexanones to produce furanylidene-benzofuran or benzofuran structures, respectively.

Keywords: benzofuran, furanylidene-benzofuran, benzoquinone, heteroannulation, one-pot reaction

\section{Introduction}

Heterocyclic compounds possessing the benzofuran core [1], of either natural or synthetic origin [2], are very important due to their exhibition of various biological activities. This has led to numerous investigations to design procedures for the synthesis of benzofuran based structures [3,4] and to study their biological behavior [5] as antioxidant [6], anticancer [7], antimicrobial [8], antitumor [9], and immunomodulatory [10] agents. As a result, the extensive physiological properties and the high natural occurrence of benzofuran derivatives have resulted in their use as versatile biodynamic and useful therapeutic agents. Important natural examples include moracins [11], cicerfuran [12], and conocarpan [13], while bufuralol [14], amiodarone [15], and ailanthoidol [16] are representative derivatives of biologically active synthetic benzofuran molecules (Fig. 1).

\footnotetext{
*Corresponding author: M. Saeed Abaee, Organic Chemistry Department, Chemistry and Chemical Engineering Research Center of Iran, P.O. Box 14335-186, Tehran, Iran;

E-mail: abaee@ccerci.ac.ir

Maryam Pirouz and Mohammad M. Mojtahedi, Organic Chemistry Department, Chemistry and Chemical Engineering Research Center of Iran, P.O. Box 14335-186, Tehran, Iran

Pernille Harris, Technical University of Denmark, DK-2800, Copenhagen, Denmark; e-mail: ph@kemi.dtu.dk
}

The broad spectrum of biochemical activities of various benzofurans has led to many investigations to prepare specific target structures from natural sources or via synthetic methods. Several arylbenzofurans were extracted from the stem bark [17], root bark [18], and leaves [19] of various mulberry trees, some of which were also prepared via multistep syntheses [20,21]. Notable methods for the synthesis of benzofurans include metalfree cyclization of ortho-hydroxystilbenes mediated by hypervalent iodine reagents [22], Ru-catalyzed isomerization [23] of appropriate precursors [24], cross-coupling of alkali-metal salts of silanols with aromatic halides [25], Pd-catalyzed addition of potassium aryltrifluoroborates to aliphatic nitriles [26], Sonogashira coupling of $O$-iodoanisoles with terminal alkynes followed by electrophilic cyclizations [27], and one-pot Pd-catalyzed coupling of ortho-bromophenols with enolizable ketones [28].

In the framework of our studies on the synthesis of various heterocyclic systems [29-31], and in continuation of our program on the use of cyclohexenone derivatives 1a-c in the synthesis [32-34], we decided to take advantage of the reactivity of cyclohexenone derivatives for possible coupling with benzoquinone (BQ), as shown in Scheme 1 for the heteroannulation of $\mathbf{1 a}$ with $\mathrm{BQ}$. This work resulted in the one-pot synthesis of benzofuran and furanylidenebenzofuran systems 2-4 in PhMe/AcOH (4:1) medium.

\section{Results and discussion}

Confident in the application of [3+2] heteroannulations in the preparation of benzofuran structures, we first targeted the synthesis of $\mathbf{2}$. For this purpose, we reacted 1a with $\mathrm{BQ}$ in a refluxing $\mathrm{PhMe} / \mathrm{AcOH}$ mixture, in which $81 \%$ of 2 was obtained after $24 \mathrm{~h}$ (Scheme 1). It is noteworthy that the synthesis of $\mathbf{2}$ was previously reported via a threestep process taking 6 days and achieving an overall yield of about 80\% [35], whereas we could access 2 through a single step reaction (Scheme 2). Mechanistically, the reaction is probably going through a formal [3+2] process, and presumably a cyclic transition state $\left(\mathbf{1 a}-\mathrm{BQH}^{+}\right)$is involved. Protonation of $\mathrm{BQ}$ in acidic conditions and formation of 


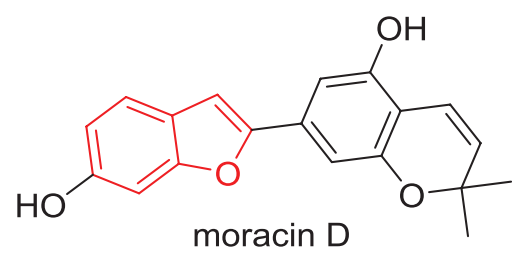<smiles>COc1cc2c(cc1-c1cc3ccc(O)cc3o1)OCO2</smiles><smiles>C/C=C/c1ccc2c(c1)[C@H](C)[C@H](c1ccc(O)cc1)O2</smiles><smiles>CCc1cccc2cc(C(O)CNC(C)C)oc12</smiles><smiles>CCCc1oc2ccccc2c1C(=O)c1cc(I)c(OCC)c(I)c1</smiles><smiles>COc1cc(-c2cc3cc(/C=C/CO)cc(OC)c3o2)ccc1O</smiles>

ailanthoidol

Figure 1 Important bioactive benzofuran containing structures<smiles>O=C1C=CC(=O)C=C1</smiles><smiles>O=C1C=CCCC1</smiles><smiles>C[CH]C</smiles>

Scheme 1 One-pot synthesis of 2

$\mathrm{BQH}^{+}[36]$ and its participation in hetrocycloadditions have precedence [37].

To gain some understanding of the process, we replaced $\mathbf{1 a}$ with $\mathbf{1 b}$. Treatment of BQ with $\mathbf{1 b}$ (Table 1) in refluxing $\mathrm{PhMe} / \mathrm{AcOH}$ solution for 3 days gave a complex mixture of products from which $m$-cresol, hydroquinone (HQ), and low yields of product 3 were identified (entry 1). The presence of a HQ skeleton in the structure of $\mathbf{3}$ and the formation of $m$-cresol as a side product suggested that a redox process could be involved. Therefore, similar reactions were performed replacing BQ with $\mathrm{HQ}$. When $\mathrm{HQ}$ and $\mathbf{1} \mathbf{b}$ were used, no formation of $\mathbf{3}$ was detected (entry 2), while a repeat of each reaction in the absence of $\mathbf{1} \mathbf{b}$ was also unsuccessful (entries 3-4). In contrast, a mixture of $\mathrm{BQ}$ and HQ produced a 70\% yield of 3 after an $18 \mathrm{~h}$ reflux in $\mathrm{PhMe} / \mathrm{AcOH}$ (entry 5). It is noteworthy that 3 belongs to the group of furanylidene-benzofuran heterocycles which contain both benzofuran and additional lactone moieties and are important for their pigment [38] and biochemical [39] properties.

To further understand the process, we repeated the reactions in the presence of $\mathrm{CD}_{3} \mathrm{CO}_{2} \mathrm{D}$, in which the same results were obtained (entry 6), proving the lack of the participation of acetic acid in the structure of the product. Similarly, use of cyclohexa-1,4-diene (CHD), as a radical scavenger [40], halted the reaction completely, supporting the inclusion of a redox process in the reaction (entry 7). Changing the solvent (entries 8-12) or the acid reagent (entries 13-16) did not improve the results. The use of two other BQ derivatives (2,5-dimethylcyclohexa2,5-diene-1,4-dione, 2,5-DMBQ, entry 17 and 2,6-dimethylcyclohexa-2,5-diene-1,4-dione, 2,6-DMBQ, entry 18) gave no respective products, as would be expected from their more electron rich nature.

To confirm that a hydrogen donor source such as $\mathbf{1 b}$ or HQ is needed for the reaction to proceed, we replaced $\mathbf{1 b}$ with either $\mathbf{1 c}$ or $\mathbf{1 d}$ and repeated the reactions in the absence of HQ (Scheme 3). Thus, with 2:1 mixtures of BQ and 1c (or 1d) no detectable reactions were observed.

Based on the results, a pathway was proposed in which $\mathrm{BQ}$ is first protonated to $\mathrm{BQH}^{+}$[36]. This hypothetical intermediate is stabilized via ring opening to a conjugated oxo-bis-enone moiety, which in turn is attacked by water to form the hydroxyethylidene-furanone intermediate. Further oxidation of this intermediate by $\mathrm{BQ}$ and its coupling with the resulting HQ, followed by the final lactonization, gives 3 (Scheme 4).

The structure of $\mathbf{3}$ was identified based on its NMR spectra. In ${ }^{1} \mathrm{H}$ NMR, the presence of two doublets and one doublet of doublets signals at about 6.8-7.2 ppm was in accordance with the $\mathrm{HQ}$ unit, while two doublet signals at 8.4 and $7.0 \mathrm{ppm}$ were indicative of the unsaturated lactone ring. Similarly, DEPT-135, COSY, HSQC, and APT experiments supported the formation of the suggested structure. To confirm, a single crystal of $\mathbf{3}$ was prepared and subjected to X-ray crystallographic experiments. Fig. 2 clearly supports the assignment.

Based on these results, we decided to design a pathway in which a similar combination of $\mathrm{BQ}$ structures would occur via an elimination reaction as opposed to a redox process. For this purpose, we selected 2,6-dichlorobenzoquinone $\left(\mathrm{BQCl}_{2}\right)$, which is more susceptible to protonation 
<smiles>O=C1C=CC(=O)C=C1</smiles>

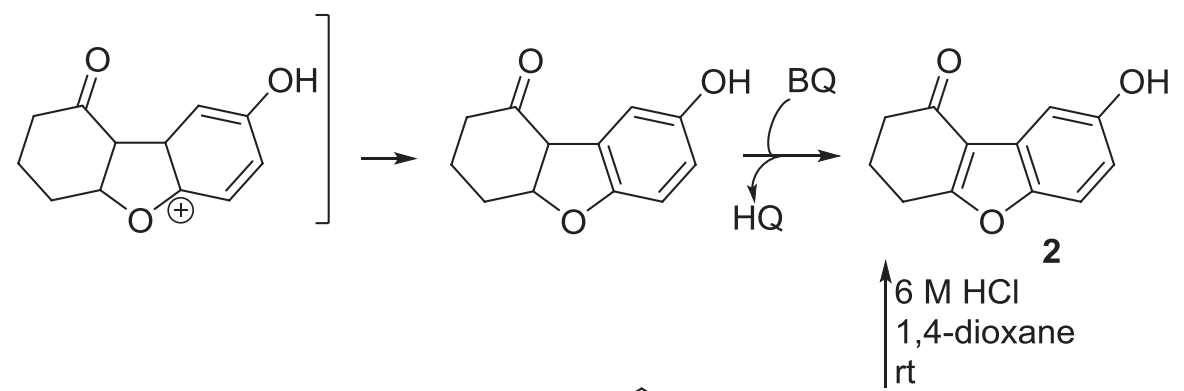<smiles>OCCC(C(O)CO)C(F)(F)F</smiles><smiles>O=C1C=CC2(C=C1)OCCO2</smiles>

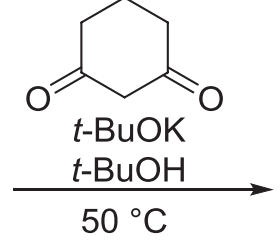<smiles></smiles>

$H Q$

Scheme 2 Stepwise $v$ s one-pot synthesis of $\mathbf{2}$

Table 1 Optimization of the synthesis of $\mathbf{3}$ using $\mathbf{1 b}$<smiles>CC1=CC(=O)CCC1</smiles>

$1 \mathrm{~b}$<smiles>O=C1C=CC(=O)C=C1</smiles>
reflux<smiles>O=C1C=CC(=C2C(=O)Oc3ccc(O)cc32)O1</smiles>

\begin{tabular}{|c|c|c|c|c|c|c|}
\hline Entry & $1 \mathrm{~b}$ (equiv.) & $B Q$ (equiv.) & HQ (equiv.) & Conditions & Time (h) & Yield (\%) \\
\hline 1 & 1.0 & 2.5 & 0.0 & $\mathrm{AcOH}, \mathrm{PhMe}$ & 72 & 15 \\
\hline 2 & 1.0 & 0.0 & 2.5 & $\mathrm{AcOH}, \mathrm{PhMe}$ & 72 & 0 \\
\hline 3 & 0.0 & 1.0 & 0.0 & $\mathrm{AcOH}, \mathrm{PhMe}$ & 72 & 0 \\
\hline 4 & 0.0 & 0.0 & 1.0 & $\mathrm{AcOH}, \mathrm{PhMe}$ & 72 & 0 \\
\hline 5 & 0.0 & 2.0 & 1.0 & $\mathrm{AcOH}, \mathrm{PhMe}$ & 18 & 70 \\
\hline 6 & 0.0 & 2.0 & 1.0 & $\mathrm{CD}_{3} \mathrm{CO}_{2} \mathrm{D}, \mathrm{PhMe}$ & 18 & 70 \\
\hline 7 & 0.0 & 2.0 & 1.0 & $\mathrm{CHD}, \mathrm{AcOH}, \mathrm{PhMe}$ & 72 & 0 \\
\hline 8 & 0.0 & 2.0 & 1.0 & $\mathrm{AcOH}, \mathrm{CHCl}_{3}$ & 18 & 0 \\
\hline 9 & 0.0 & 2.0 & 1.0 & $\mathrm{AcOH}, \mathrm{H}_{2} \mathrm{O}$ & 18 & 0 \\
\hline 10 & 0.0 & 2.0 & 1.0 & $\mathrm{AcOH}$, mesitylene & 18 & 55 \\
\hline 11 & 0.0 & 2.0 & 1.0 & AcOH, xylene & 18 & 53 \\
\hline 12 & 0.0 & 2.0 & 1.0 & $\mathrm{AcOH}$, benzene & 18 & 33 \\
\hline 13 & 0.0 & 2.0 & 1.0 & $\mathrm{CF}_{3} \mathrm{CO}_{2} \mathrm{H}, \mathrm{PhMe}$ & 18 & 0 \\
\hline 14 & 0.0 & 2.0 & 1.0 & $\mathrm{HCO}_{2} \mathrm{H}, \mathrm{PhMe}$ & 18 & 67 \\
\hline 15 & 0.0 & 2.0 & 1.0 & PTSA, PhMe & 18 & 0 \\
\hline 16 & 0.0 & 2.0 & 1.0 & $\mathrm{HCl}, \mathrm{PhMe}$ & 18 & 0 \\
\hline 17 & 0.0 & $2.0^{\mathrm{b}}$ & 1.0 & $\mathrm{AcOH}, \mathrm{PhMe}$ & 18 & 0 \\
\hline 18 & 0.0 & $2.0^{c}$ & 1.0 & $\mathrm{AcOH}, \mathrm{PhMe}$ & 18 & 0 \\
\hline
\end{tabular}

asolated yields. ${ }^{\mathrm{b} B Q}$ was replaced with 2,5-DMBQ. 'BQ was replaced with 2,6-DMBQ. 
[41], and has the potential to produce dibenzofurans, when reacted with ethyl 2-methyl-4-oxocyclohex-2-ene1-carboxylate (Hagmann ester, 1e). This would occur by taking advantage of a possible facile $\mathrm{HCl}$ elimination to couple the two reactants and reach a tricyclic dibenzofuran target structure (Scheme 5). As a result, a facile regioselective coupling was observed, giving 4.

The mechanism of the reaction presumably goes through the formation of $\mathrm{BQCl}_{2} \mathrm{H}^{+}$. This species is formed upon treatment of the reactants with $\mathrm{AcOH}$, while $\mathbf{1 e}$ is also enolized to dienol $\mathbf{1} \mathbf{e}^{\prime}$ under the acidic conditions. Then, the enol 1 $\mathbf{e}^{\prime}$ attacks the electron-poor $\mathrm{BQCl}_{2} \mathrm{H}^{+}$to form 4'. Rearrangement of the double bond to a more stable conjugated position promotes the ring closure and the process is followed by $\mathrm{HCl}$ elimination and a final dehydration/aromatization step to form 4 (Scheme 6). The structure of the product was elucidated with NMR spectroscopy techniques and was confirmed with X-ray crystallographic analysis (Fig. 3).

\section{Conclusion}

In summary, we successfully conducted the synthesis of benzofuran and furanylidene-benzofuran systems via the one-pot coupling of $\mathrm{BQ}$ with either itself or cyclohexenone

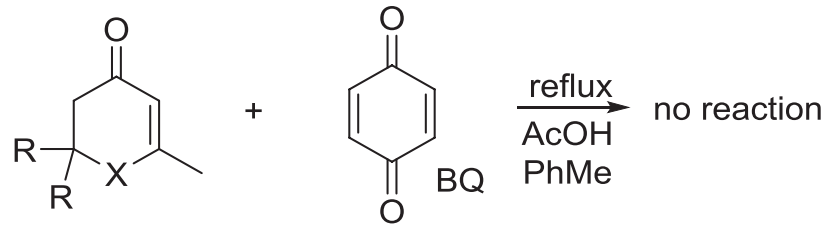

1c: $\mathrm{R}=\mathrm{Me}, \mathrm{X}=\mathrm{CH}_{2}$

1d: $\mathrm{R}=\mathrm{H}, \mathrm{X}=$ none

Scheme 3 Reactions in the presence of 1c-d under refluxing acidic conditions, using no coupling reagent. The benzofuran formation occurs either through $[3+2]$ heteroannulation of the starting cyclohexenone moiety with $\mathrm{BQ}$ derivatives (in the case of $\mathbf{2}$ and $\mathbf{4}$ ) or the "dimerization" of BQ (in the case of $\mathbf{3}$ ), followed by either spontaneous oxidation (aromatization) or elimination (dehydration) steps. The procedures are clearly effective in producing the target compounds under inexpensive conditions, in shorter time periods and with fewer reaction steps when compared to the previous reports for known products [35]. Based on these results, we are currently developing the procedures to use a broader spectrum of reactants, such as phenols and thiophenols.

\section{Experimental}

Melting points are uncorrected. FT-IR spectra were recorded using $\mathrm{KBr}$ disks on a Bruker Vector-22 spectrometer. NMR spectra were recorded at $400 \mathrm{MHz}$ for ${ }^{1} \mathrm{H}$ NMR and $101 \mathrm{MHz}$ for ${ }^{13} \mathrm{C}$ NMR on a Bruker Ascend $400 \mathrm{MHz}$ spectrometer in DMSO- $d_{6}$ solutions using TMS as an internal standard reference. Chemical shift values $(\delta)$ are reported in ppm relative to the residual solvent signal in DMSO, while coupling constants $(J)$ are given in Hz. Multiplicities are reported as s (singlet), d (doublet), dd (doublet of doublets), m (multiplet) and etc. Flash column chromatography was performed using silica gel $60(0.035-0.070 \mathrm{~mm}$ particle size). Elemental analyses were performed using a Thermo Finnigan Flash EA 1112 instrument. LCMS analysis was carried out on a Waters ACQUITY UPLC system with a PDA and SQD2 electrospray detector and a Thermo Accucore C18 $2.6 \mu \mathrm{m}, 2.1 \times 50 \mathrm{~mm}$ column. TLC experiments were carried out on pre-coated silica gel plates using hexanes/EtOAc as the eluent. Chemicals and starting materials were purchased from commercial sources.

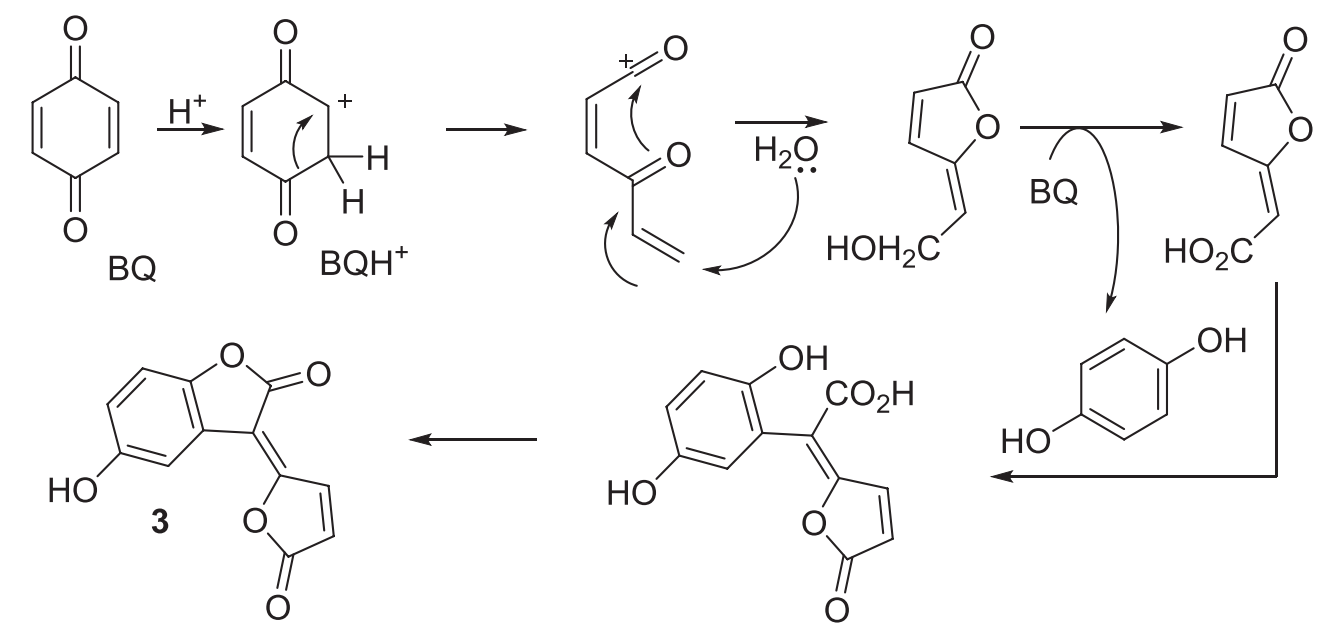




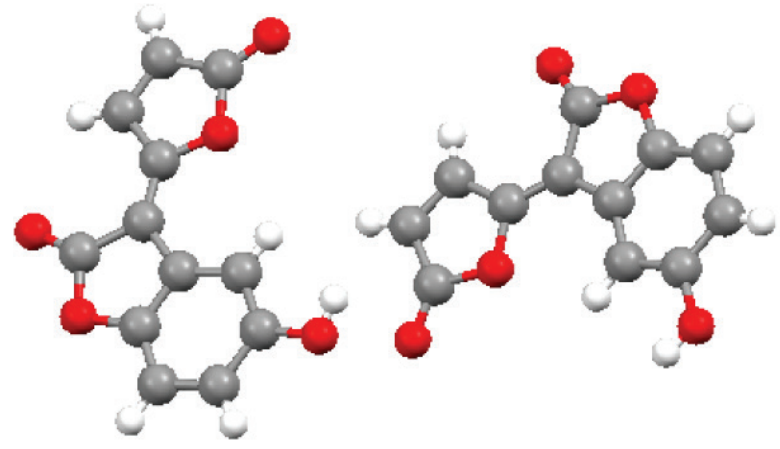

Figure 2 ORTEP representation of $\mathbf{3}$, thermal ellipsoids set at the $40 \%$ probability level
Product 2 [35] was known and identified by NMR spectra. Products $\mathbf{3}$ and $\mathbf{4}$ were new and were characterized by analysis of their ${ }^{1} \mathrm{H}$ NMR, ${ }^{13} \mathrm{C}$ NMR, IR, mass spectra, and X-ray crystallography.

\section{Synthesis of 8-hydroxy-3,4-dihydrodibenzo[b,d]furan-} 1(2H)-one (2)

To a solution of PhMe (4.0 mL) and glacial AcOH $(1.0 \mathrm{~mL})$ was added 1a (100 $\mu \mathrm{L}, 1.0 \mathrm{mmol})$ and benzoquinone (216 mg, $2.0 \mathrm{mmol}$ ) and the mixture was refluxed for 24 hours. Saturated aqueous $\mathrm{NaHCO}_{3}$ (excess) was added<smiles>O=C1C=C(Cl)C(=O)C(Cl)=C1</smiles>

$\mathrm{BQCl}_{2}$<smiles>CCOC1CCC(=O)C=C1C</smiles>

$1 e$ $\underset{\text { reflux, } 3 \mathrm{~h}}{\stackrel{\mathrm{PhMe}, \mathrm{AcOH}}{\longrightarrow}}$ $83 \%$<smiles>CCOC(=O)c1ccc2oc3c(Cl)cc(O)cc3c2c1C</smiles>

Scheme 5 Synthesis of 4<smiles>O=C1C=C(Cl)C(=O)C(Cl)=C1</smiles><smiles>CCOC(=O)C1CCC(=O)C=C1C</smiles><smiles>CCC</smiles><smiles>ClCCCCl</smiles><smiles>CCCC1=CCC(C(=O)OCC)C(C)=C1</smiles><smiles>CCOC(=O)C1=C(C)C2(Cl)C(=CC1)OC1(O)C(Cl)=CC(O)=CC12Cl</smiles><smiles>CCOC(=O)C1CC=C(OC2(O)C(Cl)=CC(=O)C=C2Cl)C=C1C</smiles><smiles>CCOC(=O)c1ccc2oc3c(Cl)cc(O)cc3c2c1C</smiles> 


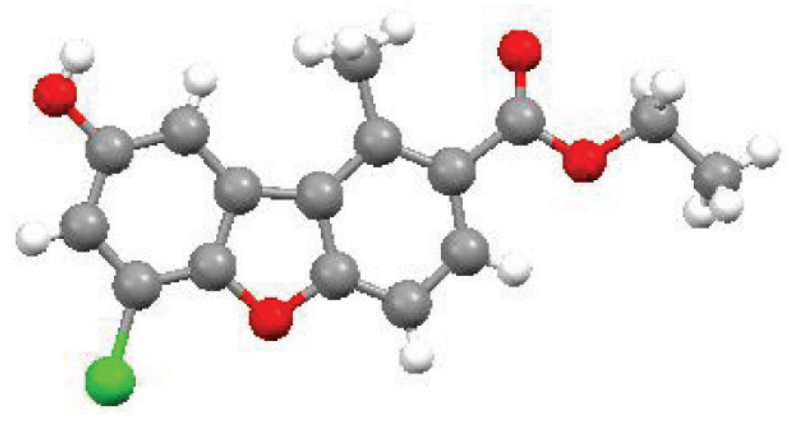

Figure 3 ORTEP representation of $\mathbf{4}$, thermal ellipsoids set at the $40 \%$ probability level

to the mixture and the organic layer was diluted with EtOAc $(10.0 \mathrm{~mL})$. The organic layer was dried over $\mathrm{Na}_{2} \mathrm{SO}_{4}$ and after evaporation of the volatiles, the residue was purified with flash chromatography over silica gel using EtOAc/hexanes (1:5) to obtain 2 .

White crystals (81\%); ${ }^{1} \mathrm{H}$ NMR (400 MHz, DMSO- $\left.d_{6}\right)$ $\delta 9.40(\mathrm{~s}, 1 \mathrm{H}), 7.43(\mathrm{~d}, J=9.0 \mathrm{~Hz}, 1 \mathrm{H}), 7.26(\mathrm{~d}, J=2.5 \mathrm{~Hz}, 1 \mathrm{H})$, $6.75(\mathrm{dd}, J=2.5,9.0 \mathrm{~Hz}, 1 \mathrm{H}), 3.03-3.00(\mathrm{~m}, 2 \mathrm{H}), 2.49-2.48$ (m, 2H), 2.19-2.12 (m, 2H); ${ }^{13} \mathrm{C}$ NMR (101 MHz, DMSO- $\left.d_{6}\right)$ $\delta$ 194.8, 172.5, 155.1, 148.3, 124.6, 115.9, 113.6, 112.2, 106.1, 33.8, 23.7, 22.4; MS: m/z $202\left(\mathrm{M}^{+}\right)$.

\section{Synthesis of (E)-5-hydroxy-3-(5-oxofuran-2(5H)-ylidene) benzofuran-2(3H)-one (3)}

To a solution of PhMe (4.0 mL) and glacial AcOH (1.0 mL) was added benzoquinone (216 mg, $2.0 \mathrm{mmol}$ ) and hydroquinone (110 mg, $1.0 \mathrm{mmol}$ ) and the mixture was refluxed for 18 hours. Saturated aqueous $\mathrm{NaHCO}_{3}$ (excess) was added to the mixture and the organic layer was diluted with EtOAc $(10.0 \mathrm{~mL})$. The organic layer was dried over $\mathrm{Na}_{2} \mathrm{SO}_{4}$ and after evaporation of the volatiles, the residue was purified with flash chromatography over silica gel using EtOAc/hexanes (1:5) to obtain 3.

Red crystals (70\%); $210{ }^{\circ} \mathrm{C}$ (decomposes); ${ }^{1} \mathrm{H}$ NMR (400 MHz, DMSO-d $) \delta 9.65(\mathrm{~s}, 1 \mathrm{H}), 8.43(\mathrm{~d}, J=5.5 \mathrm{~Hz}, 1 \mathrm{H})$, $7.18(\mathrm{~d}, J=2.5 \mathrm{~Hz}, 1 \mathrm{H}), 7.10(\mathrm{~d}, J=8.5 \mathrm{~Hz}, 1 \mathrm{H}), 7.01(\mathrm{~d}, J=5.5 \mathrm{~Hz}$, $1 \mathrm{H}), 6.85(\mathrm{dd}, J=2.5,8.5 \mathrm{~Hz}, 1 \mathrm{H}) ;{ }^{13} \mathrm{C}$ NMR (101 MHz, DMSO$\left.d_{6}\right) \delta 168.0,166.9,155.4,154.5,146.9,141.2,125.2,122.0$, 119.2, 120.4, 111.1, 106.0; IR (KBr) v 1064, 1466, 1766, 2922, $3467 \mathrm{~cm}^{-1}$; MS: m/z $230\left(\mathrm{M}^{+}\right)$. Anal. Calcd for $\mathrm{C}_{12} \mathrm{H}_{6} \mathrm{O}_{5}: \mathrm{C}$, 62.62; H, 2.63. Found: C, 62.50; H, 2.75.

\section{X-ray data for 3}

$\mathrm{C}_{12} \mathrm{H}_{6} \mathrm{O}_{5}, \mathrm{M}=230.17 \mathrm{~g} / \mathrm{mol}$, triclinic system, space group $P-1$, $a=7.0075(7), b=9.9741(7), c=14.5706(12) \AA, \alpha=81.108(6)$, $\beta=79.856(8), y=70.532(8), V=940.10(15) \AA^{3}, Z=4$,
$D c=1.626 \mathrm{~g} / \mathrm{cm}-3, \mu(\mathrm{Mo}-\mathrm{K} \alpha)=0.129 \mathrm{~mm}^{-1}$, crystal dimension of $0.1 \times 0.1 \times 0.1 \mathrm{~mm}$. The X-ray data collection for 3 was performed on an Agilent Supernova Diffractometer. Data processing was done using CrysAlisPro (Agilent Technologies). The structure was solved by using SHELXS, and structure refinement was carried out with SHELXL [42]. The non-hydrogen atoms were refined anisotropically by full matrix least-squares on $F 2$ values to final $\mathrm{R} 1=0.0822$, $w \mathrm{R} 2=0.2630$, and $\mathrm{S}=1.009$ with 309 parameters using 4647 independent reflection $\left(\theta\right.$ range $\left.=3.19-29.65^{\circ}\right)$. Hydrogen atoms were included on ideal positions using riding coordinates. Crystallographic data for $\mathbf{3}$ have been deposited with the Cambridge Crystallographic Data Centre. Copies of the data can be obtained, free of charge, on application to The Director, CCDC-2046512, Union Road, Cambridge CB2 1EZ, UK. Fax: +44 1223336033 or e-mail: deposit@ccdc.cam.ac.uk.

\section{Synthesis of ethyl 6-chloro-8-hydroxy-1- methyldibenzo[b,d]furan-2-carboxylate (4)}

To a solution of $\mathrm{PhMe}(4.0 \mathrm{~mL})$ and glacial $\mathrm{AcOH}(1.0 \mathrm{~mL})$ was added 1e $(160 \mu \mathrm{L}, 1.0 \mathrm{mmol})$ and $\mathrm{BQCl}_{2}(264 \mathrm{mg}$, $1.5 \mathrm{mmol}$ ) and the mixture was refluxed for 3 hours. Saturated aqueous $\mathrm{NaHCO}_{3}$ (excess) was added to the mixture and the organic layer was diluted with EtOAc $(10.0 \mathrm{~mL})$. The organic layer was dried over $\mathrm{Na}_{2} \mathrm{SO}_{4}$ and after evaporation of the volatiles, the residue was purified with flash chromatography over silica gel using EtOAc/hexanes (1:5) to obtain 4.

White crystals (83\%); mp $=183-184^{\circ} \mathrm{C} ;{ }^{1} \mathrm{H}$ NMR $(400$ MHz, DMSO- $\left.d_{6}\right) \delta 9.99(\mathrm{~s}, 1 \mathrm{H}), 7.91(\mathrm{~d}, J=9.0,1 \mathrm{H}), 7.58(\mathrm{~d}$, $J=9.0 \mathrm{~Hz}, 1 \mathrm{H}), 7.45(\mathrm{~d}, J=2.0 \mathrm{~Hz}, 1 \mathrm{H}), 7.06(\mathrm{~d}, J=2.0 \mathrm{~Hz}, 1 \mathrm{H})$, 4.32 (q, $J=7.0 \mathrm{~Hz}, 2 \mathrm{H}), 2.88$ (s, 3H), 1.35 (t, $J=7.0 \mathrm{~Hz}, 3 \mathrm{H}$ ); ${ }^{13}$ CNMR (101 MHz, DMSO- $d_{6}$ ) $\delta 167.3,157.6,154.7,145.6$, 136.8, 130.6, 126.2, 125.9, 123.9, 115.9, 116.0, 109.8, 107.9, 61.2, 17.3, 14.6 ; IR (KBr) v 3344, 2853, 1681, 1258, 1073, $779 \mathrm{~cm}^{-1}$; MS: $m / z=304[\mathrm{M}]^{+}$. Anal. Calcd for $\mathrm{C}_{16} \mathrm{H}_{13} \mathrm{ClO}_{4}: \mathrm{C}, 63.07 ; \mathrm{H}$, 4.30. Found: C, 63.25; H, 4.52.

\section{X-ray data for 4}

$\mathrm{C}_{16} \mathrm{H}_{13} \mathrm{ClO}_{4}, \mathrm{M}=304.71 \mathrm{~g} / \mathrm{mol}$, monoclinic system, space group $P 2_{1} / c, a=12.0554(3), b=7.2442(1), c=15.3414(3) \AA$, $\beta=$ 95.954(2), $V=1332.56(5) \AA^{3}, Z=4, D c=1.519 \mathrm{~g} / \mathrm{cm}-3$, $\mu(\mathrm{Cu}-\mathrm{K} \alpha)=2.672 \mathrm{~mm}^{-1}$, crystal dimension of $0.25 \times 0.20 \times$ $0.18 \mathrm{~mm}$. The structure was solved using SHELXS and refined with SHELXL [40]. The non-hydrogen atoms were refined anisotropically by full matrix least-squares on $F 2$ values to final $\mathrm{R} 1=0.0470, w \mathrm{R} 2=0.1360$, and $\mathrm{S}=1.025$ 
with 193 parameters using 2792 independent reflection $\left(\theta\right.$ range $\left.=3.69-76.56^{\circ}\right)$. Hydrogen atoms were inserted at ideal positions.

Research funding: The Research Council at CCERCI is acknowledged for financial support of this work.

Conflict of interest: Authors state no conflicts of interest.

Data availability statement: Crystallographic data for 4 have been deposited with the Cambridge Crystallographic Data Centre. Copies of the data can be obtained, free of charge, on application to The Director, CCDC-2046513, Union Road, Cambridge CB2 1EZ, UK. Fax: +44 1223336033 or e-mail: deposit@ccdc.cam.ac.uk. All other data generated or analyzed during this study are included in this published article and its supplementary information file.

\section{References}

[1] Khanam H, Shamsuzzaman. Bioactive Benzofuran derivatives: A review. Eur J Med Chem. 2015 Jun;97:483-504.

[2] Chand K, Rajeshwari, Hiremathad A, Singh M, Santos MA, Keri RS. A review on antioxidant potential of bioactive heterocycle benzofuran: natural and synthetic derivatives. Pharmacol Rep. 2017 Apr;69(2):281-95.

[3] Kadieva MG, Oganesyan ÉT. Methods for the synthesis of benzofuran derivatives [review]. Chem Heterocycl Compd. 1997;33(11):1245-58.

[4] More KR. Review on synthetic routes for synthesis of benzofuran-based compounds. J Chem Pharm Res. 2017;9:210-20.

[5] Naik R, Harmalkar DS, Xu X, Jang K, Lee K. Bioactive benzofuran derivatives: moracins A-Z in medicinal chemistry. Eur J Med Chem. 2015 Jan;90:379-93.

[6] Rindhe SS, Rode MA, Karale BK. New benzofuran derivatives as an antioxidant agent. Indian J Pharm Sci. 2010 Mar;72(2):231-5.

[7] Coşkun D, Tekin S, Sandal S, Coşkun MF. Synthesis, characterization, and anticancer activity of new benzofuran substituted chalcones. J Chem. 2016;2016:7678486

[8] Ashok D, Kumar RS, Gandhi DM, Sarasija M, Jayashree A, Adam S. Solvent-free microwave-assisted synthesis and biological evaluation of 2,2-dimethylchroman-4-one based benzofurans. Heterocycl Commun. 2016;22(6):363-8.

[9] Othman DI, Abdelal AM, El-Sayed MA, El Bialy SA. Novel benzofuran derivatives: synthesis and antitumor activity. Heterocycl Commun. 2013;19(1):29-35.

[10] Khaleghi F, Jantan I, Din LB, Yaacob WA, Khalilzadeh MA, Bukhari SN. Immunomodulatory effects of 1-(6-hydroxy-2isopropenyl-1-benzofuran-5-yl)-1-ethanone from Petasites hybridus and its synthesized benzoxazepine derivatives. J Nat Med. 2014 Apr;68(2):351-7.

[11] Mitsuo T, Shigemitsu N, Shoji U, Tadashi M, Akira S, Kokichi T. Moracin $C$ and $D$, new phytoalexins from diseased mulberry. Chem Lett. 1978;7(11):1239-40.
[12] Damodar K, Kim JK, Jun JG. Unified syntheses of gramniphenols $\mathrm{F}$ and $\mathrm{G}$, cicerfuran, morunigrol $\mathrm{C}$ and its derivative. Tetrahedron Lett. 2016;57(10):1183-6.

[13] Silva AR, Polo EC, Martins NC, Correia CR. Enantioselective oxy-Heck-matsuda arylations: expeditious synthesis of dihydrobenzofuran systems and total synthesis of the neolignan (-)-conocarpan. Adv Synth Catal. 2018;360(2):346-65.

[14] Weerawarna SA, Geisshüsler SM, Murthy SS, Nelson WL. Enantioselective and diastereoselective hydroxylation of bufuralol. Absolute configuration of the 7-(1-hydroxyethyl)2-[1-hydroxy-2-(tert-butylamino)ethyl]benzofurans, the benzylic hydroxylation metabolites. J Med Chem. 1991 Oct;34(10):3091-7.

[15] Iqbal N, Iqbal N, Maiti D, Cho EJ. Access to multifunctionalized benzofurans by aryl nickelation of alkynes: efficient synthesis of the anti-arrhythmic drug amiodarone. Angew Chem Int Ed Engl. 2019 Oct;58(44):15808-12.

[16] Lin SY, Chen CL, Lee YJ. Total synthesis of ailanthoidol and precursor XH14 by Stille coupling. J Org Chem. 2003 Apr;68(7):2968-71.

[17] Wang SK, Duh CY. Cytotoxic cyclopenta[b]benzofuran derivatives from the stem bark of Aglaia formosana. Planta Med. 2001 Aug;67(6):555-7.

[18] Piao SJ, Qiu F, Chen LX, Pan Y, Dou DQ. New Stilbene, Benzofuran, and coumarin glycosides from Morus alba. Helv Chim Acta. 2009;92(3):579-87.

[19] Chan EW, Wong SK, Tangah J, Inoue T, Chan HT. Phenolic constituents and anticancer properties of Morus alba (white mulberry) leaves. J Integr Med. 2020 May;18(3): 189-95.

[20] Kinoshita T, Ichinose K. A short step convenient synthesis of 2-phenylbenzofuran form 3-phenylcoumarin. Heterocycles. 2005;65(7):1641-54.

[21] Kunyane P, Sonopo MS, Selepe MA. Synthesis of isoflavones by tandem demethylation and ring-opening/ cyclization of methoxybenzoylbenzofurans. J Nat Prod. 2019 Nov;82(11):3074-82.

[22] Singh FV, Wirth T. Hypervalent iodine mediated oxidative cyclization of $o$-hydroxystilbenes into benzo- and naphthofurans. Synthesis. 2012;44(8):1171-7.

[23] van Otterlo WA, Morgans GL, Madeley LG, Kuzvidza S, Moleele $\mathrm{SS}$, Thornton N, et al. An isomerization-ring-closing metathesis strategy for the synthesis of substituted benzofurans. Tetrahedron. 2005;61(32):7746-55.

[24] Varela-Fernández A, González-Rodríguez C, Varela JA, Castedo L, Saá C. Cycloisomerization of aromatic homo- and bis-homopropargylic alcohols via catalytic Ru vinylidenes: formation of benzofurans and isochromenes. Org Lett. 2009 Nov;11(22):5350-3.

[25] Denmark SE, Smith RC, Chang WT, Muhuhi JM. Cross-coupling reactions of aromatic and heteroaromatic silanolates with aromatic and heteroaromatic halides. J Am Chem Soc. 2009 Mar;131(8):3104-18.

[26] Wang X, Liu M, Xu L, Wang Q, Chen J, Ding J, et al. Palladiumcatalyzed addition of potassium aryltrifluoroborates to aliphatic nitriles: synthesis of alkyl aryl ketones, diketone compounds, and 2-arylbenzo[b]furans. J Org Chem. 2013 Jun;78(11):5273-81. 
[27] Yue D, Yao T, Larock RC. Synthesis of 2,3-disubstituted benzo[b] furans by the palladium-catalyzed coupling of $o$-iodoanisoles and terminal alkynes, followed by electrophilic cyclization. J Org Chem. 2005 Dec;70(25):10292-6.

[28] Eidamshaus C, Burch JD. One-pot synthesis of benzofurans via palladium-catalyzed enolate arylation with $o$-bromophenols. Org Lett. 2008 Oct;10(19):4211-4.

[29] Mojtahedi MM, Mehraban M, Darvishi K, Abaee MS. Ultrasound mediated synthesis of dihydropyrano [3,2- $d][1,3]$ dioxin7-carbonitrile derivatives in $\mathrm{H}_{2} \mathrm{O} / \mathrm{EtOH}$ medium. Heterocycl Commun. 2017;23(2):91-5.

[30] Abaee MS, Akbarzadeh E, Shockravi A, Mojtahedi MM, Mehraki E, Khavasi HR. Three-component anti selective Mannich reactions in a tetrahydro-4-pyranone system by using PDAG-Co catalyst. Heterocycl Commun. 2014;20(2):123-8.

[31] Poursharifi MJ, Mojtahedi MM, Abaee MS, Hashemi MM. The first in situ synthesis of 1,3-dioxan-5-one derivatives and their direct use in Claisen-Schmidt reactions. Heterocycl Commun. 2019;25(1):85-90.

[32] Abaee MS, Mojtahedi M, Zahedi MM, Sharifi R, Mesbah AW, Massa W. Synthesis and structural elucidation of novel bisarylmethylidenes of cyclic enones. Synth Commun. 2007;37(17):2949-57.

[33] Mojtahedi MM, Abaee MS, Zahedi MM, Jalali MR, Mesbah AW, Massa W, et al. Facile solvent-free synthesis and structural elucidation of styrylcyclohex-2-enone derivatives. Monatsh Chem. 2008;139(8):917-21.

[34] Abaee MS, Mohammadi M, Mojtahedi M, Halvagar MR. Halvagar. M. R. Synthesis and Diels-Alder reactions of novel styrylcyclohexenol dienes: a general pathway for the synthesis of tricyclic lactone and octahydronaphthalene systems. Tetrahedron Lett. 2016;57(36):4094-7.

[35] Craven PG, Taylor RJ. Total synthesis and structural confirmation of ( \pm )-cuevaene A. Tetrahedron Lett. 2012;53(40):5422-5.

[36] Bhongale PV, Joshi SS, Mali NA. Selective monoalkylation of hydroquinone in the presence of $\mathrm{SO}_{3} \mathrm{H}$-functionalized ionic liquids as catalysts. Chem Pap. 2020;74(12): 4461-71.

[37] Pushkarskaya E, Wong B, Han C, Capomolla S, Gu C, Stoltz BM, et al. Single-step synthesis of 3-hydroxycarbazoles by annulation of electron-rich anilines and quinones. Tetrahedron Lett. 2016;57(50):5653-7.

[38] von Nussbaum F, Rüth M, Spiteller P, Hübscher-Weissert T, Löbermann F, Polborn K, et al. Coloured artefacts formed by oxidation of benzene-1,2,4-triol and $\beta$-dopa during the extraction of cortinarius violaceus (Agaricales) with alcohols. Eur J Org Chem. 2012;2012(2):380-90.

[39] Dang PH, Nguyen HX, Nguyen NT, Le HN, Nguyen MT. $\alpha$-Glucosidase inhibitors from the stems of Embelia ribes. Phytother Res. 2014 Nov;28(11):1632-6.

[40] Walton JC, Studer A. Evolution of functional cyclohexadienebased synthetic reagents: the importance of becoming aromatic. Acc Chem Res. 2005 Oct;38(10):794-802.

[41] Kepler S, Zeller M, Rosokha SV. Anion- $\pi$ complexes of halides with $p$-benzoquinones: structures, thermodynamics, and criteria of charge transfer to electron transfer transition. J Am Chem Soc. 2019 Jun;141(23):9338-48.

[42] Sheldrick GM. A short history of SHELX. Acta Crystallogr A. 2008 Jan;64(Pt 1):112-22. 